\title{
A CRONOLOGIA DA DESCOBERTA DOS TRANSMISSORES DA MALÁRIA NA AMAZONIA BRASILEIRA
}

\author{
LEONIDAS M. DEANE
}

Instituto Oswaldo Cruz, Departamento de Entomologia, Caixa Postal 926, 20010 Rio de Janeiro, RJ, Brasil

Chronology of the discovery of malaria vectors in the Brazilian Amazon - In the Amazon Region of Brazil, during the first three decades of this century, anophelines of the subgenus Nyssorhynchus not precisely identified to species were regarded as the probable malaria vectors. In 1931 and 1933 Anopheles darlingi, and in 1942-1946 An. aquasalis were confirmed as carriers, the former in the interior, the latter along the coast, because of their habits and salivary gland infections. An. albitarsis and An. braziliensis seemed to be occasional, secondary vectors. Forty years later, through immunological tests, other species are being pointed as naturally infected: An. triannulatus, An. nuneztovari, An. oswaldoi, An. strodei, An. galvaoi and An. peryassui. The importance of all incriminated species except An. darlingi (the main vector wherever present) and An. aquasalis has yet to be measured.

Key words: Anopheline vectors - malaria - Amazon - history

Logo depois de ter sido descoberto, no último ano do século passado, que a malária humana é transmitida por anofelinos, pesquisadores vindos à Amazônia procuraram identificar representantes desse grupo de mosquitos e eventualmente estabelecer sua relação com a doença.

Quase nada se conhecia sobre os mosquitos daquela região quando, em 1900, chegou ao Pará uma missão da Escola de Medicina Tropical de Liverpool, com Herbert Durham e Walter Myers, para estudar a febre amarela e as condiçōes sanitárias do vale amazônico, onde empresas inglesas iriam construir os portos de Belém e Manaus e instalar uma linha de navegaçāo fluvial. Ambos os pesquisadores adoeceram de febre amarela, Durham sarou mas Myers (aos 28 anos) morreu. Em 1902, Durham publicou um relato detalhado sobre a saúde na área, no qual já refere a presença e abundância de um Anopheles argyrotarsus (que poderia ser qualquer espécie do subgênero Nyssorhynchus) e a existência de um outro anofelino, posteriormente identificado ao $A n$. nimbus.

$\mathrm{Na}$ tese de doutoramento que Celestino Bourroul apresentou em 1904 à faculdade de Medicina da Bahia, "Mosquitos do Brasil", Lutz cita três espécies de anofelinos encontradas em Belém e Manaus, uma sendo o Anopheles mediopunctatus e as outras duas com designações que hoje nāo se pode associar a espécies conhecidas.

Em 1905 apareceu o lindamente ilustrado "Os Mosquitos do Pará", em que Emílio Goeldi, o fundador do Museu que hoje tem seu nome, nos relata a presença de dois anofelinos, Cellia argyrotarsis e Cellia argyrotarsis var. albipes, chamando todavia a atenção para que o último nome seria impróprio, porque o mosquito tinha um anel preto no 5? tarsômero posterior e, portanto, pergunta ele, "porque não chamá-lo tarsimaculata?". Naturalmente, sob esses dois nomes muitas espécies de Nyssorhynchus poderiam ser incluídas, pertencentes às atuais Seções Argyritarsis e Albimanus, correspondentes aos Nyssorhynchus sem e com o dito anel negro.

Àquela época, a idéia que se tinha era de que qualquer espécie de anofelino seria boa transmissora da malária e, sendo assim, os nomes específicos nāo tinham a mesma importância que têm hoje. Por isso, quando Antonio Peryassú, que desde estudante freqüentava o Instituto de Manguinhos, publicou em 1908 sua tese de doutoramento "Os Culicídeos do Brazil", um alentado volume de 408 páginas, ele se refere a seis espécies de anofelinos encontradas na Amazônia, considerando todas como transmissoras habituais da malária: seriam elas An. lutzi, An. mediopunctatus e $A n$. nimbus e 
três difíceis de correlacionar com os nomes atuais, embora duas fossem Nyssorhynchus e a última uma Kerteszia.

No ano seguinte, dois outros cientistas da Escola de Medicina Tropical de Liverpool vieram à Amazônia - R. Newstead e Wolferstan Thomas (este último, aliás, tendo sido posteriormente o médico de nossa familia durante minha infância em Manaus). Trabalhando nessa e em outras cidades da Amazônia eles publicaram, em 1910, "The mosquitoes of the Amazon Region", no qual registram três espécies de anofelinos: Cellia argyrotarsis, Cellia albimana e Stethomyia nimba. Da primeira, encontrada muitas vezes em casas ("undoubtedly a domestic species"), dão um desenho que permite, com segurança, identificar-se o hoje chamado Anopheles darlingi, que àquela época ainda não havia sido descrito. A segunda espécie seria o anofelino mais freqüente na Amazônia, também encontrado nas casas, mas só ao crepúsculo vespertino.

Em 1910 Oswaldo Cruz foi à Amazônia, convidado pelo Governo do Pará para iniciar a campanha contra a febre amarela e pela Estrada de Ferro Madeira-Mamoré para opinar sobre o controle da malária; lá voltou em 1913, por um pedido da Superintendência da Defesa da Borracha, a fim de estabelecer bases para a profilaxia da região. Nesse último ano, também Carlos Chagas esteve na Amazônia com igual finalidade. Ambos encontraram lá os mesmos anofelinos referidos por Newstead e Thomas - isto é argyrotarsis, albimana e nimba - mas consideraram que os transmissores locais da malária deveriam ser os dois primeiros, trazendo assim à baila a noção de que é entre os anofelinos do subgênero Nyssorhynchus, então colocados no gênero Cellia, que estão os vetores do paludismo na região.

Durante os 10 anos seguintes Peryassú fez freqüentes viagens ao Pará, seu estado natal, identificando anofelinos e organizando projetos limitados, de controle do paludismo com medidas antilarvárias. Em sua nova monografia, "Os Anophelineos do Brasil", aparecida em 1921, ele menciona 10 espécies de anofelinos na Amazônia, mas desta vez frisa que a existência da malária depende praticamente da presença das Cellia, isto e, de Nyssorhynchus, dos quais os principais seriam Cellia argyritarsis (que podia ser qualquer espécie da atual Seção Argyritarsis, que inclui o nessa época ainda não descrito $A n$. darlingi), Ce. albimana Ce. tarsimaculata (quaisquer espécies da Seçāo Albimanus, onde se situa, entre outros, o hoje chamado An. aquasalis).

Durante a VII Expedição Hamilton Rice à Amazônia, feita em conjunto com a Universidade de Harvard, e cujos resultados foram publicados em 1926 por R. P. Strong e colaboradores, três espécies de anofelinos foram apanhados por Joseph Bequaert, o entomologista do grupo: duas são hoje reconhecidas como An. mattogrossensis e $A$ n. peryassui e a terceira era um Nyssorhynchus com anel negro no $5^{\circ}$ tarsômero posterior e que foi citado como An. tarsimaculata e encarado como "one which generally carries malaria in the Amazon Basin".

Foi em 1926 que o entomologista Francis Metcalf Root, da Universidade de Johns Hopkins, trabalhando na Baixada Fluminense, Rio de Janeiro, descreveu uma nova espécie de Nyssorhynchus, separando-a das demais e denominando-a $A n$. darlingi, em homenagem ao Dr. Samuel Taylor Darling, que fora professor titular de Higiene da Faculdade de Medicina de São Paulo entre 1918 e 1922 . A descoberta desse mosquito, depois considerado um importante transmissor da malária, veio mostrar que as designaçōes anteriores das espécies sem anel negro no 5 o tarsômero posterior nem sempre eram válidas.

A primeira comprovação de uma espécie de anofelino como transmissora da malária na Amazônia deve-se a Nelson Davis (1931), da Fundaçāo Rockefeller. Em 1930, durante um grave surto de paludismo nos subúrbios de Belém, ele achou seis espécies de anofelinos: $A n$. darlingi, An. tarsimaculatus, An. intermedius, An. shannoni, An. mediopunctatus e An. nimbus. Dissecando 171 darlingi encontrou um com esporozoitas nas glândulas salivares. Foi essa a primeira infecção malárica constatada em mosquito amazônico e Davis opinou que esse anofelino "was certainly the chief malaria vector in the region studied". O chamado $A n$. tarsimaculatus não foi incriminado dessa vez porque parecia preferir o sangue de animais, poucos exemplares sendo achados nas casas.

Um inquérito mais amplo foi realizado na Amazônia em 1931 por Raymond Shannon (1933). Este entomologista, também da Fundaçāo Rockefeller, foi quem descobrira em 1930 em Natal, Rio Grande do Norte, que o mosqui- 
to africano Anopheles gambiae havia invadido - Brasil. Shannon descreveu aquele inquérito num artigo fundamental, "The Anophelines of the Amazon Valley". Visitou uma dúzia de localidades, desde Belém, na foz do rio até as fronteiras do Perú e da Bolívia. Encontrou 14 espécies de anofelinos, dos quais somente o darlingi freqüentava as casas em números elevados e dentre 56 exemplares dissecados em Porto Velho, Rondônia, 1 tinha esporozoitas nas glândulas salivares. Por isso, bem como pelo endofilismo do mosquito e pela coincidência entre sua presença e a da malária, Shannon o considerou "doubtlessly the most important vector of the disease in the area". Entre os outros mosquitos ele menciona que tarsimaculatus era o anofelino mais comum na região, mas parecia ser relativamente pouco importante devido à sua exofilia.

Na Amazônia o inquérito seguinte de mosquitos foi efetuado por Henry Kumm e Oswaldo Novis (1938), ainda da Fundação Rockefeller, na Ilha de Marajó, Pará, em 1935 e 1936 (ocasião em que eu, estudante de medicina e morando defronte do laboratório da Fundação em Belém, aprendi a identificar mosquitos com Dr. Kumm). Como o inquérito visava a transmissão da febre amarela silvestre, que ocorre mais durante o dia, as capturas de mosquitos, em isca humana, foram feitas geralmente do amanhecer ao anoitecer. Dos anofelinos obtidos dentro das casas quase todos eram darlingi, espécie que não foi achada nas muito mais numerosas capturas extradomiciliares.

Foi entretanto no Instituto Evandro Chagas, sediado em Belém, que se fizeram os estudos mais abrangentes e detalhados sobre os anofelinos da Amazônia e sua relação com a malária. Iniciados pela equipe de Evandro Chagas em 1939, foram continuados após a morte deste aos 35 anos de idade, em 1940, por outras equipes, até 1949. A primeira destas era constituída por Augusto Leopoldo Ayroza Galvão, Reinaldo Damasceno e Artur Porto Marques e trabalhou em Belém, publicando seus resultados em 1942. Galvão pertencia ao Departamento de Parasitologia da Faculdade de Medicina da Universidade de São Paulo, então dirigida pelo Prof. Samuel Pessoa e já tinha efetuado importantes estudos sobre os anofelinos de São Paulo e regiões vizinhas. Damasceno e Marques eram do Pará e haviam participado da equipe de Evandro, que lá realizou os estudos pioneiros sobre o calazar americano. Em Belém, os esfor- ços se concentraram na determinação dos trans. missores locais e no melhor conhecimento de seus hábitos de importância para o controle da doença. Os autores confirmaram o papel do darlingi como transmissor, mas o então chamado tarsimaculatus foi também encontrado naturalmente infectado com esporozoitos e encarado pela primeira vez como importante vetor na Amazônia, apesar de sua relativa exofilia e zoofilia. Foi ainda visto que, enquanto o darlingi se encontrava nos trechos mais altos da cidade, em bairros de terra firme, o tarsimaculatus existia nas partes mais baixas, ou várzeas, sujeitas à invasão da água salobra das marés. O darlingi trasmitia a malária principalmente dentro das casas durante toda a noite, nas horas mais altas, o tarsimaculatus fora das casas e ao crepúsculo vespertino. Os criadouros do darlingi eram principalmente grandes coleções de água doce, os do tarsimaculatus de água salobra e de tamanho e tipo muito variado. Todas as outras espécies locais de anofelinos-braziliensis, oswaldoi, triannulatus, peryassui, intermedius, mediopunctatus, eiseni e nimbus não teriam importância epidemiológica.

Um surto de malária na Ilha de Marajó, em 1942, levou Galvão \& Damasceno (1944) a procurar seu transmissor; incriminaram uma subespécie que então criaram, An. albitarsis. domesticus, que diferiria do albitarsis da localidade-tipo, Baradero, Argentina, e do interior de São Paulo, por detalhes morfológicos e, biologicamente, por ser endófilo e antropófilo; mas não dissecaram exemplares em busca da infecção natural. A existência dessa subespécie vem sendo recentemente contestada (Rios et al., 1984; Rosa-Freitas, 1988).

Foi depois de 1945 que o nome de Anopheles aquasalis Curry, 1932, começou a ser usado no Brasil para o anofelino de água salobra da Amazônia. Naquele ano, Causey e colaboradores optaram pela adoçāo daquele nome, mostrando que a denominação de tarsimaculatus foi dada por Goeldi (1905) com base na descrição de exemplares de, pelo menos, duas espécies.

Os importantes estudos de Galvão e colaboradores (1942) em Belém puseram em evidência os principais aspectos da biologia dos anofelinos presentes naquela cidade e suas relações com a malária. Naquele ano e nos subseqüentes, estudos da ecologia dos anofelinos foram estendidos a outras áreas da Amazônia por uma equipe organizada por Ottis Causey, Maria Paumgart- 
ten Deane e eu. Esse grupo, recém-chegado do Nordeste, onde participara da campanha contra o Anopheles gambiae, passou a atuar no Instituto Evandro Chagas, nessa ocasiāo incorporado ao então fundado Serviço Especial de Saúde Pública, ou SESP, como seu laboratório central. O SESP foi criado pelos governos do Brasil e dos Estados Unidos em 1942, a fim de proteger a saúde de milhares de nordestinos importados para trabalhar nos seringais da Amazônia, visando incrementar a produção de borracha após a tomada das plantações do Oriente pelos japoneses na Segunda Guerra Mundial. Entre 1942 e 1944 um inquérito entomológico foi conduzido em cerca de 60 localidades em todos os Estados e Territórios da regiāo. Longas viagens foram feitas pelos cientistas, enquanto técnicos em muitas localidades capturavem fêmeas de anofelinos sugando pessoas ou animais, dentro e fora de casas, isolando-as em frascos individuais e enviando-as, juntamente com as respectivas desovas, ao laboratório em Belém, onde as posturas eram criadas para a obtenção de larvas e adultos de ambos os sexos, o que ajudou a classificar com exatidão as espécies de cada localidade. Além da distribuição geográfica, esses estudos aumentaram o conhecimento sobre o comportamento de larvas e adultos. Os resultados, que enunciaremos a seguir, foram publicados por Causey et. al. (1946) como monografia do American Journal of Hygiene e por Deane (1947) e Deane et al. (1948) na revista do SESP. Um total de mais de 107.000 anofelinos adultos, 350.000 larvas e 45.000 desovas de 29 espécies foram obtidos e o exame das glândulas salivares de 5.000 fêmeas levou à comprovação de que o darlingi e o aquasalis eram os únicos transmissores primá. rios da malária humana na região, o primeiro no interior e o segundo no litoral. De um modo geral, os dados que haviam sido obtidos por Galvão e colaboradores (1942) em Belém foram confirmados para toda a Amazônia. O darlingi mostrou-se a espécie mais endofílica (embora só excepcionalmente se tenha capturado algum macho nos domicílios) e, no interior das casas (em Belém e Ananindeua), se viu que as fêmeas repousam principalmente nos dois metros mais baixos das paredes (Deane \& Damasceno, 1948), o que permitiu considerável economia no controle da malária pela aspersão intradomiciliar de DDT. O horário da hematofagia variou de lugar a lugar, mas de um modo geral as fêmeas invadiam as casas ao crepúsculo vespertino, aumentando de número no decorrer da noite ou na primeira metade da noite e, como as fêmeas ficavam dentro das casas por algumas horas após se alimentar, podiam ser aí achadas nas primeiras horas da manhã. Nas capturas extradomiciliares os picos crepusculares podiam ultrapassar o do meio da noite. $\mathrm{O}$ antropofilismo foi verificado em capturas simultâneas em pessoas e animais e comprovado numa experiência: em um grande mosquiteiro dentro do qual pernoitavam um homem e sete animais (cavalo, boi, cabra, cão, gato, porco e galinha), fêmeas de darlingi criadas no laboratório eram soltas ao pôr do sol e, na manhã seguinte, $50 \%$ delas continha sangue humano determinado por provas de precipitina, enquanto em experiência semelhante menos de $11 \%$ dos aquasalis haviam se alimentado no homem (Deane et al., 1949). A presença do darlingi coincidia sempre com a da makária, mesmo onde a sua densidade era baixa e, onde ele não existia, também não havia malária, exceto no litoral, onde estava presente o aquasalis. Tanto darlingi como aquasalis foram várias vezes achados naturalmente infectados com esporozoitos nas glândulas salivares. A transmissão pelo darlingi ocorria principalmente dentro das casas e à noite, mas esporozoitas também foram encontrados em exemplares capturados picando de dia e ao exterior; um exemplo ocorreu com minha mulher, Maria Deane, que achou esporozoitas num darlingi que a estava sugando às 10 horas da manhã, no convés descoberto de uma lancha no meio do Rio Arari, Ilha de Marajó (Deane et al., 1948). Entre 1947 e 1948, nos arredores de Belém, pela primeira vez na Amazônia brasileira, foi estudada a distribuição vertical de mosquitos na floresta através de capturas simultâneas em iscas humanas colocadas no solo e em plataformas a 5, 10 e 15 metros de altura; dez das 60 espécies de mosquitos eram anofelinos; o darlingi preferiu sugar perto do chão, mas se alimentou também, em proporções decrescentes, nos outros níveis, $12 \%$ na copa (Deane et al., 1955); este fato indica que em áreas onde existe a malária simiana os esporozoitas encontrados por dissecação em darlingi não são obrigatoriamente de origem humana. Devido à endofilia do darlingi em Belém, o controle da malária nos bairros altos da cidade, onde ele era o transmissor, foi feito com sucesso pelo SESP, pela aspersão de DDT nas paredes internas das casas, nos quarteirões mais próximos, dentre os que rodeavam o grande criadouro permanente, a represa de Utinga; quanto ao aquasalis, pelos seus criadouros preferenciais, o SESP controlou a malá ria por ele transmitida nos bairros baixos de Belém, construindo um dique com compor- 
tas que impediam a entrada da água salobra nas enchentes das marés. $\mathrm{O}$ albitarsis, muito espalhado e abundante na Amazônia, não foi, na ocasiāo, considerado transmissor primário na região; apesar do seu endofilismo e antropofilismo sua presença nem sempre coincidia com a da malária e quando havia essa coincidência o darlingi também estava presente, além do que não foram achados esporozoitas nas glândulas de quase mil exemplares examinados: considerou-se que o albitarsis poderia ser um transmissor ocasional, onde o darlingi fosse responsável pelo grosso da transmissāo. Outro anofelino, o braziliensis, foi achado com esporozoitas no mesmo inquérito numa localidade (Tamucuri, Pará) onde o darlingi era o transmissor principal. As 25 espécies restantes de anofelinos entāo encontradas na Amazônia não foram suspeitadas de veicular o paludismo: eram exófilas, zoófilas, não havia paralelismo entre sua presença e a da malária e todos os exemplares dissecados de 11 espécies estavam livres de plasmódios (Deane et al., 1948). Os estudos feitos na Amazônia pelos pesquisadores do SESP na década de 1940 foram tão detalhados que, nos 40 anos seguintes, só uma espécie a mais foi lá encontrada: Anopheles neivai, da qual algumas larvas foram colhidas em Manaus por Cerqueira (1961) e muitas fêmeas adultas, na Estrada Manaus-Itacoatiara, por Deane et al. (1966); as fêmeas dessa Kerteszia bromelícola foram quase todas apanhadas na copa da floresta onde havia malária simiana e 1 neivai dentre 72 tinha esporozoitas, de modo que se tornou suspeito de transmitir a malária de macacos na região, mas não se pensa que lá ele veicule a malária humana, porque é acrodendrófilo e sua distribuição não coincide com a da doença.

Durante a maior parte das décadas de 1950 e 1960 o sucesso da campanha anti-malárica na maioria do território brasileiro levou à impres. são de que a erradicação estava à vista e esse otimismo foi acompanhado de uma queda do interesse pelo estudo dos anofelinos. Não se fizeram mais inquéritos em larga escala como os realizados nos anos de 1940, mas a partir da década de 1970 houve alguns esforços localizados, bem sucedidos e que merecem atenção.

Em 1977, durante grave epidemia de malária entre indígenas do Território de Roraima, junto à fronteira venezuelana, José Ferraroni e Jack Hayes viram que o darlingi era quase o único anofelino presente e, de 40 exemplares dissecados, 1 tinha esporozoitas. Hayes
\& Derek Charlwood (1977), trabalhando com o darlingi no Estado do Amazonas, notaram que nas casas que haviam sido aspergidas com DDT, os mosquitos entravam para sugar, mas não repousavam nas paredes, ao contrário do que ocorria nas casas não tratadas. Charlwood \& Hayes (1979) verificaram ser diferente o ciclo de hematofagia do darlingi em três localidades de Roraima, Amazonas e Mato Grosso. Charlwood \& Wilkes (1978) estudaram a distribuição etária das fêmeas de darlingi picando pessoas durante a noite em Aripuanã, Mato Grosso, verificando que a proporção de nulí. paras era muito maior nos dois picos crepusculares. A variação estacional de uma populaçāo de darlingi foi observada por Hayes \& Charlwood (1979) na estrada Manaus-Boa Vista, usando iscas humanas dentro e fora de casas, confirmando o que Galvão e colaboradores (1942) haviam verificado em Belém, isto é, que a densidade desse mosquito aumenta na estaçāo seca e cai no período das chuvas intensas; viram ainda que esse mosquito suga dentro de casa durante toda a noite, mas em maiores números durante a primeira metade da noite $\mathrm{e}$ que, ao exterior, o cume de hematofagia era perto da meia-noite, mas a maioria das picadas se dava na segunda metade da noite.

Por essa época a idéia dominante era de que a malária do interior da Amazônia era veiculada quase exclusivamente pelo darlingi. Mas algumas observações apontavam para a possibilidade de outras espécies atuarem como transmissoras independentes. Num longo trecho da Rodovia Transamazônica, a oeste de Marabá, no Pará. Kenneth Dixon et al. (1979) e Donald Roberts et al. (1979) verificaram que havia áreas malarígenas onde não encontraram o darlingi ou outro anofelino endófilo, mas que entre os mosquitos capturados havia numerosos exemplares de $A n$. triannulatus, An. nuneztovari, e An. oswaldoi, que suspeitaram serem transmissores extradomiciliares da doença. Uma dessas espécies, o triannulatus, foi alvo de um estudo de Charlwood (1981) em Aripuanã, Mato Grosso; capturas em isca humana mostraram que só $5 \%$ das fêmeas eram obtidas dentro das casas, as restantes sendo coletadas ao exterior, perto da floresta, ao crepúsculo, circunstância em que os moradores adquiririam a malária. A exofilia e os hábitos crepusculares desse mosquito já haviam sido constatados por Deane et al. (1948), que na época dissecaram 240 exemplares da Amazônia, sem encontrar esporozoitas, mas referem que "como se alimenta facilmente em indivi- 
duos humanos é de crer que possa acidentalmente transmitir a malária nos lugares onde for abundante".

Uma revisão dos anofelinos do subgènero Nyssorhynchus da Amazônia foi feita por Michael Feran \& Kanneth Linthicum, em 1981, com a descrição da morfologia e da bionomia, bem como a importância médica de todas as espécies. Incluem como vetores o darlingi, o aquasalis e o que chamam de An. allopha (= albitarsis), e como transmissores secundários ou potenciais o braziliensis e o evansi, as demais espécies aparentemente não tendo importância epidemiológica.

Na presente década alguns inquéritos abrangentes foram ou estão sendo feitos.

O primeiro foi realizado por Wanderli Tadei e colaboradores, do INPA, em 1980 e 1981, numa área influenciada pela Hidrelétrica de Tucuruí, no Pará, com os resultados publicados em 1983. Perto de 10.000 anofelinos de 12 espécies foram obtidos. O darlingi foi o mais abundante (33\% do total). seguido por nuneztovari $(22 \%)$, triannulatus $(17 \%)$ e oswaldoi (11\%). O darlingi foi considerado o vetor importante, sua presença sempre coincidindo com a da malária. Picava dentro e fora de casas durante toda a noite, enquanto as outras espécies se alimentavam ao exterior e ao crepúsculo. As larvas do darlingi criavam nos mesmos tipos de depósitos descritos por Galvão e colaboradores em 1942, em Belém, e por Deane et al. (1948) em vários pontos da Amazônia. Tadei e colaboradores sugeriram que ao redor dos agrupamentos humanos a floresta fosse substituida por vegetaçāo pequena e esparsa, para proteger os moradores do darlingi criado na vizinhança. Têm dúvidas sobre a possibilidade das outras três espécies comuns funcionarem como transmissoras importantes, porque nas áreas onde coexistiam com a malária, também encontraram o darlingi.

Até há pouco tempo, no Brasil, a infecção natural de anofelinos vinha sendo avaliada pelo encontro de esporozoitas ao exame a fresco das glândulas salivares dos mosquitos mortos na ocasião e a espécie de esporozoitas não podia ser determinada.

Recentemente um novo tipo de inquérito visando comprovar as espécies de transmissores da malária na Amazônia foi efetuado por um grupo de pesquisadores da Universidade de New York, do Instituto Oswaldo Cruz e do Instituto de Medicina Tropical de São Paulo e cujos resultados foram publicados em 1986 por Mércia Arruda e colaboradores. De 1983 a 1985, em cinco localidades malarígenas do Pará, foram capturados anofelinos, dos quais exemplares das seis espécies mais numerosas foram submetidos a uma prova imunoradiométrica (IRMA) (Zavala et al., 1982) e uma enzimática (ELISA) (Burkot et al., 1984) usando anticorpos monoclonais espécie-específicos para antígenos circunsporozoíticos que permitem identificar as espécies de plasmódios nos mosquitos. Encontraram infecção natural em cinco espécies de anofelinos: darlingi, albitarsis, nuneztovari, triannulatus e oswaldoi. As três últimas não haviam sido anteriormente encontradas infectadas no Brasil. Esporozoitas de Plasmodium vivax foram detectados nas cinco espécies, de Pl. falciparum somente em darlingi e oswaldoi.

Esses achados sobre a existência na Amazônia brasileira, de novos transmissores além dos aí identificados há mais de 40 anos, levaram o Instituto Oswaldo Cruz a investigar a transmisș̃o da malária no Estado de Rondônia, onde estão ocorrendo alterações ambientais devidas à imigração maciça, à mineração desenfreada e a grandes projetos de colonização e onde, em 1988, foram registrados $278 \mathrm{mil}$ casos de malária, $50 \%$ do total de $560 \mathrm{mil}$ assinalados em todo o Brasil. Tais estudos, dos quais participaram pesquisadores dos Departamentos de Entomologia e Imunologia, foram realizados nos Municípios de Ariquemes e Porto Velho. Pôde-se constatar que o darlingi correspondeu a mais de $77 \%$ de todos os anofelinos capturados, foi quase a única espécie encontrada nas casas, embora sendo muito mais abundante ao exterior, na imediata vizinhança das casas (que são dedetizadas e talvez por isso), sugando pessoas durante toda a noite, mas principalmente ao pôr do sol e na primeira metade da noite. Dezessete outras espécies também foram encontradas, porém em números muito menores: triannulatus $(7,5 \%)$, evansae $(3 \%)$, albitarsis $(2,8 \%)$, oswaldoi $(2,3 \%)$, strodei $(1,7 \%)$, a soma das demais 13 espécies correspondendo a 5,3\%. Provas imunoradiométricas com anticorpos monoclonais revelaram esporozoitas de $P l$. falciparum em 32 darlingi e 1 braziliensis, e de Pl. vivax em 5 darlingi e 5 triannulatus. Foi concluído que na área em estudo o darlingi é, de longe, o mais importante vetor de malária, que está 
transmitindo junto às casas e nas primeiras horas da noite; os outros dois transmissores estariam veiculando o paludismo ao ar livre, na floresta, longe das habitações (Deane et al., 1988; Lourenço-de-Oliveira et al., 1989).

Quase simultaneamente com estes, outros estudos foram feitos sobre os anofelinos, seus hábitos e relação com a malária, na cidade de Ariquemes, por Tadei et al. (1988). Encontraram 15 espécies de anofelinos, o darlingi sendo, de longe a predominante, seguido por triannulatus e oswaldoi. Enquanto a primeira pica até tarde da noite, as outras se alimentam quase somente ao crepúsculo vespertino. Usando o método ELISA assinalaram infecçōes naturais por esporozoitos de Plasmodium vivax em darlingi, triannulatus, nuneztovari, strodei, galvaoi e peryassui, as três últimas pela primeira vez no Brasil; de $P$. falciparum somente em darlingi.

Como esta história revela, os resultados dos estudos recentes sobre os anofelinos da Amazônia diferem dos procedidos lá há quatro décadas por dois aspectos principais: por alguns hábitos do darlingi e pelo achado de infecçōes naturais por plasmódios em várias espécies de anofelinos tidos anteriormente como sem importância epidemiológica local. O darlingi era considerado muito endófilo, transmitindo a malária principalmente dentro das casas, o que explicava o sucesso do controle da doença pela aspersão intra-domiciliar de DDT; hoje as evidências são de que essa transmissão se faz principalmente no peridomicílio. No passado, quando as infecçōes por esporozoitos eram baseadas no exame a fresco das glândulas salivares, quase exclusivamente o darlingi no interior e o aquasalis no litoral costumavam ser encontrados infectados (além de uma vez, braziliensis com esporozoitos e albitarsis com oocistos); agora, quando se usam métodos imunológicos que vantajosamente permitem o diagnóstico das espécies de plasmódio albergadas pelos mosquitos, vêm-se assinalando a infecção em espécies que nunca haviam sido antes achadas naturalmente albergando parasitos da malária na regiāo, como triannulatus, nuneztovari, strodei, galvaoi e peryassui.

Em outro artigo fazemos conjeturas sobre explicações para essas divergências (Lourenço. de-Oliveira et al., 1989). Quero, entretanto, terminar registrando uma preocupação. Nas provas imunológicas que vêm sendo feitas na Amazònia para revelar a infecção natural de anofelinos por plasmódios, têm-se usado os mosquitos inteiros e não separadamente seus tóraxes e abdomens. Como Posthma et al. (1988) mostraram recentemente que anticorpos monoclonais antiesporozoitos também reagem com oocistos imaturos, os resultados positivos dessas provas nāo significam, necessariamente, a existência de esporozoitos nas glândulas salivares - condição para que os mosquitos sejam considerados transmissores da malária.

\section{REFERẼNCIAS}

ARRUDA, M. E.; CARVALHO, M.; NUSSENZWEIG, R. S.; MARICIC, M.; FERREIRA, W. \& COCHRANE, A. H., 1986. Potential vectors of malaria and their different susceptibility to Plasmodium falciparum and Plasmodium vivax in Northern Brazil, identified by immunoassay. Am.J. Trop. Med. Hyg., 35: 873-881.

BURKOT, T. R.; ZAVALA, F.; GWADZ, R. W.; COLLINS, F. H.; NUSSENZWEIG, R. S. \& ROBERTS, D. R., 1984. Identification of malaria-infected mosquitoes by a two-side enzyme-linked immuno. sorbent assay. Am. J. Trop. Med. Hyg., 33: 227 231.

CAUSEY, O. R.; DEANE, L. M. \& DEANE, M. P., 1945. Anopheles aquasalis vs. Anopheles tarsimaculatus as the name for the brackish-water Anopheline of Central and South America and the Caribean Islands. J. Nat. Malaria Soc., 43: 234-250.

CAUSEY, O. R.; DEANE, L. M. \& DEANE, M. P., 1946. Studies on Brazilian Anophelines from the Northeast and Amazon Regions. Am. J. Hyg., monogr. series n. $18,58 \mathrm{p}$.

CERQUEIRA, N., 1961. Distribuição geográfica dos mosquitos da Amazonia (Diptera, Culicidae, Culicinae). Rev. Bras. Ent., 10:11-168.

CHAGAS, C., 1913. Notas sobre a epidemiologia do Amazonas. Brazil-Med., 27: 450-456.

CHARLWOOD, D. \& HAYES, J., 1970. Variaçōes geográficas no ciclo de picada do Anopheles darlingi Root, no Brasil. Acta Amazonica, 8:601-638.

CHARLWOOD, D. \& WILKES, T. J., 1979. Studies on the age composition of samples of Anopheles darlingi Root (Diptera, Culicidae) in Brazil. Bull. Entom. Res., 69: 337-342.

CHARLWOOD, D. \& WILKES, T. J., 1981, Observations on the biting activity of Anopheles triannulatus bachmanni from the Mato Grosso, Brazil. Acta Amazonica, 11: 67-69.

CRUZ, O., 1910. Consideraçōes sobre as condições sanitárias do Rio Madeira. Papel. Americana, Rio de Janeiro, $44 \mathrm{p}$.

CRUZ, O., 1913. Relatórios sobre as condiçōcs sanitárias do Valle do Amazonas. Tip. J. do Commer. cio, Rio de Janeiro, $106 \mathrm{p}$.

DAVIS, N., 1931. A note on the malaria carrying Anophelines in Belem, Para and Natal, Rio Grande do Norte, Brazil. Riv. di Malariol., Rome, 10:1-11.

DEANE, L. M., 1947. Observaçōes sobre a malaria na Amazônia Brasileira. Rev. Serv. Esp. Saúde Publ., I: 160 .

DEANE, L. M.; CAUSEY, O. R. \& DEANE, M. P., 1948. Notas sobre a distribuição e biologia dos Anofelinos das Regiōes Nordestina e Amazônica 
do Brasil. Rev. Serv. Esp. Saúde Publ., 1:827-965

DEANE, L. M. \& DAMASCENO, R., 1948. Altura do pouso das fêmeas de Anopheles darlingi e Anopheles aquasalis nas paredes internas das casas. Rev. Serv. Esp. Saúde Publ., 2: 501-508.

DEANE, L. M.; DAMASCENO, R. \& AROUCK, R., 1953. Distribuiçāo vertical de mosquitos em uma floresta dos arredores de Belém, Pará. Folia Clin. et Biol., 20: 101-110.

DEANE, L. M.; DANIEL-RIBEIRO, C.; LOURENCODE-OLIVEIRA, R.; OLIVEIRA-FERREIRA, J \& GUIMARAES, A. E., 1988. Study of the natural history of malaria in areas of Rondonia State, Brazil and problems related to its control. Rev. Inst. Med. Trop. Sāo Paulo, 30: 153-156.

DEANE, L. M.; FERREIRA-NETO, J. A. \& CERQUEIRA, N., 1966. Observaçōes preliminares so. bre malária de macacos no Estado do Amazonas. Rev. Brasil. Biol., 26: 405412.

DEANE, L. M.; VERNIN, C. S. \& DAMASCENO, R., 1949. Avaliação das preferências alimentares das fêmeas de Anopheles darlingi e Anopheles aquasalis em Belém, por meio de provas de precipitina. Rev. Serv. Esp. Saude Publ., Rio de Janeiro, 2: 793-808.

DIXON, K., ROBERTS, D. R., \& LLEWELLYN, C. H., 1979. Contribuiçāo ao estudo epidemiológico da malária em trechos da Rodovia Transamazônica, Brasil. Rev. Inst. Med. Trop. Säo Paulo, 21: 287292.

DURHAM, H. E., 1902. Report on the yellow fever expedition to Para. Liverpool School Trop. Med., memoir ?.

FARAN, M. \& LINTHICUM, K., 1981. A Handbook of the Amazonian species of Anopheles (Nyssor. hynchus) (Diptera, Culicidae). Mosq. System., 13: $1-81$.

FERRARONI, J. \& HAYES, J., 1977. Estudo sobre um surto de malária entre os índios Mayongong $\mathrm{e}$ Sanomã (norte de Roraima). Acta Amazonica, 7: 401406

GALVĀO A. L. A. \& DAMASCENO, R., 1944. Observaçōes sobre anofelinos do complexo albi. tarsis (Diptera, Culicidae). An. Fac. Med. S. Paulo. 20. $73 \cdot 87$

GALVÃO, A. L.; DAMASCENO, R. \& MARQUES, A. P., 1942. Algumas observações sobre a biologia dos anofelinos de importância epidemiológica em Belém do Pará. Arq. Hig., Rio de Janeiro, 12: 51. 111.

GOELDI, E., 1905. Os mosquitos do Pará. Mem. Museu Goeldi, C. Wiegandt, $154 \mathrm{p}$.

HAYES, J. \& CHARLWOOD, D., 1977. O Anopheles darlingi evita o DDT numa área de malária resistente a drogas. Acta Amazonica, 7: 289.

HAYES, J. \& CHARLWOOD, D., 1979. Dinâmica estacional de uma populaçāo de Anopheles darlingi numa área endêmica de malária no Amazonas. Acta A mazonica, 91: 79-86.

KUMM, H. \& NOVIS, A., 1938. Mosquito studies on the Ilha de Marajó, Pará, Brazil. Am. J. Hyg., 27: 488-515.

LOURENÇO-DE-OLIVEIRA, R;; GUIMARĀES, A.
E.; ARLE, M.; FERNANDES-DA-SILVA, T.; GONÇALVES CASTRO, M.; ALBUQUERQUE MOTTA, M. \& DEANE, L. M., 1989. Anopheline species, some of their habits and relation to malaria, in endemic areas of Rondonia State, Amazon region of Brazil. Mem. Inst. Oswaldo Cruz, 84: 501-514.

LUTZ, A., 1904. In Bourroul, Mosquitos do Brasil. Thesis, Fac. Med. Bahia, Brazil.

NEWSTEAD, R. \& THOMAS, H. W., 1910. The mosquitoes of the Amazon Region. Ann. Trop. Med. \& Parasit. 4: 141-149.

PERYASSU, A. G., 1908. Os Culicideos do Brazil. Typ. Leuzinger, Rio de Janeiro, 408 p.

PERYASSU, A. G., 1921. Os Anophelineos do Brasil. Impr. Nacional, Rio de Janeiro, 99 p.

POSTHUMA, G.; MEIS, J. F. G. M.; VERHAVE, J. P.; HOLLINGDAE, M. R.; PONNUNDURALT, T.; MEUWISSEN, J. H. E. T. \& GEUZE, H. J., 1988. Immunogold localization of circumsporozoite protein of the malaria parasite Plasmodium falciparum during sporogony in Anopheles ste. phensi midguts. J. Cell Biol., 46: 18-24.

RIOS, R. J.; NASCIMENTO, L. P. \& OLIVEIRA, A. C., 1984. Complexo Anopheles albitarsis: impossibilidade de separá-lo em duas subespécies, Anopheles albitarsis albitarsis e Anopheles albitarsis domesticus. Rev. Brasil. Biol., 44: 461-465.

ROBERTS, D. R.; HOCH, A. L.; PATTERSON, N. E. \& PINHEIRO, F. 1979. Programa multidisciplinario de vigilancia de las enfermedades infecciosas en zonas colidentes con la Carretera Transamazonica en Brasil. Bol. Of. Sanit. Panamer., 91: 379-398.

ROSA-FREITAS, M. G., 1988. Anopheles albitarsis Lynch-Arribálzaga, 1878. Um estudo comparativo de caracteres morfológicos, bioquímicos e comportamentais de populações de dez localidades. Tese de Mestrado, Instituto Oswaldo Cruz, Rio de Janeiro.

ROOT, F. M., 1926. Studies on Brazilian mosquitoes. I. The Anophelines of the Nyssorhynchus group. Am. J. Hyg., 6: 684-717.

STRONG, R. P.; SHATTUCK, G. C.; WHEELER, R. \& BEQUAERT, J., 1926. Medical Report of the Hamilton Rice 7th expedition to the Amazon, in conjunction with the Department of Tropical Medicine of Harvard University, 1924-1925. Harvard Univ. Press., Cambridge, 313 p.

TADEI, W.; MASCARENHAS, B. \& PODESTÂ, M., 1983. Biologia dos anofelinos amazônicos. VIII. Conhecimento sobre a distribuiçāo de espécies de Anopheles na regiāo de Tucuruí, Marabá (Pará). Acta Amazonica, 13: 103-140.

TADEI, W.; SANTOS, J. M. M.; COSTA, W. L. S. \& SCARDANA, V. M., 1988. Biologia dos anofelinos amazônicos. XII. Ocorrência de espécies de Anopheles, dinâmica da transmissão e controle da malária na zona urbana de Ariquemes, Rondonia. Rev. Inst. Med. Trop. Säo Paulo, 30: 221-251.

ZAVALA, F.; GWADZ, R. W.; COLLINS, F. H.; NUSSENZWEIG, R. S. \& NUSSENZWEIG, V., 1982. Monoclonal antibodies to circumsporozoite proteins identify the species of malaria parasites in infected mosquitoes. Nature, 299: 737-738. 